\title{
El peregrino Alí Bey, un "príncipe abasí» español del siglo XIX
}

\section{Fernando Escribano Martín}

Arbor CLXXX, 711-712 (Marzo-Abril 2005), 757-771 pp.

En los primeros años del siglo XIX Domingo Badía fue enviado con una misión no clara, aparentemente científica pero también con intenciones políticas, a Marruecos. Para tal misión se hizo pasar por Ali Bey, un príncipe abasi que volvía de Europa a su origen musulmán. No sabemos bien porqué hubo de abandonar Marruecos, y peregrinó entonces a La Meca, de donde volvió a Europa. Domingo Badía cumplió el destino de los afrancesados y, una vez en Francia, muchos años después, reintentó su aventura, en la que murió. A nosotros nos queda el relato de sus viajes, dudas sobre sus pretensiones, y la conciencia de estar ante un gran aventurero que aún no comprendemos del todo.

La vida de Domingo Badía, viajero, científico, escritor y espía es la de un personaje excepcional a camino entre dos mundos, el árabe y el occidental, que nos dejó una obra clave, su libro de viajes, una especie de transición entre la obra de uno de los últimos ilustrados y uno de los primeros viajeros románticos, que descubrió a Occidente el mundo del Mediterráneo meridional en el momento en el que Europa se planteaba su expansión por África y Asia.

Este libro, que escribió en francés, y firmó como Alí Bey, príncipe abasí, siendo él español, y comisionado de este Gobierno en una misión no trasparente por Marruecos y que le llevó hasta La Meca, es la obra de 
un científico ilustrado (que abarca lo que hoy para nosotros son ciencias distintas), pero también la de un viajero romántico, que observa el mundo que visita, que pretende analizarlo y trasformarlo, y que se debate con su mundo interior.

El libro Voyages d'Alí Bey el Abbassi en Afrique et en Asie pendant les années 1803, 1804, 1805, 1806 et 1807 (París, 1814) es uno de los pocos que publicó, y sin duda el más importante. Entre sus papeles existen numerosos memoriales, traducciones y estudios que no fueron al final publicados pero que dan la impresión de estar perfectamente terminados para ello. El libro es el punto final de una aventura fascinante tanto en su gestación como en su desarrollo. De la cual no conocemos todos los detalles, pues están implicados los servicios secretos y todo un mundo de intrigas, y de la que el único resultado claro es esta publicación. Los conocimientos adquiridos, la experiencia atesorada y los planes que albergaba, que no pudo lograr en el primer viaje, marcó el resto de su vida, y le llevó a intentar un segundo periplo, ahora con pabellón francés, con el nombre de Hash Alí Otman, en el que murió, en 1818, cerca de Damasco, quizá envenenado.

En este texto vamos a tratar de analizar la vida de Domingo Badía, las motivaciones que le movieron, los resultados obtenidos y los estudios que realizó, además de reivindicar, una vez más, su figura. Siendo como es uno de los grandes viajeros y científicos españoles, duerme, si no en el limbo del olvido, si en el del mal reconocimiento.

Las fuentes documentales sobre el personaje las encontramos sobre todo en el Arxiu Historic de Barcelona (la Colección Toda, que este personaje, Eduard Toda, trajo de París en 1889¹), en el Archivo Histórico Nacional, en el Archivo del Ministerio de Asuntos Exteriores y en la Biblioteca Central del CSIC. La bibliografía que ha generado Alí Bey ha sido amplia y con dispares opiniones sobre el personaje y su obra. En las primeras ediciones de su obra no se señalaba que Alí Bey era Domingo Badía, y sólo en 1836, ¡la primera edición en castellano! se establece la relación. El personaje, que comenzó a ser estudiado y reivindicado por estas fechas, en parte dentro del proceso de la Renaixença catalana, ha sido objeto de muy distintas valoraciones, desde un héroe incomprendido y genial, hasta un esquizofrénico víctima de sus fantasías.

Domingo Badía y Leblich nació en Barcelona el 1 de abril de 1767, y fue bautizado ese mismo día en la Seu. Hijo de Pedro, secretario del gobernador de la ciudad, el conde de Ofalia, y de Catalina Leblich, que pertenecía a una familia originaria de Wabria, junto a Bruselas, afincada en Barcelona desde el siglo XVII. 
El peregrino Alí Bey, un «príncipe abasí» español del siglo XIX

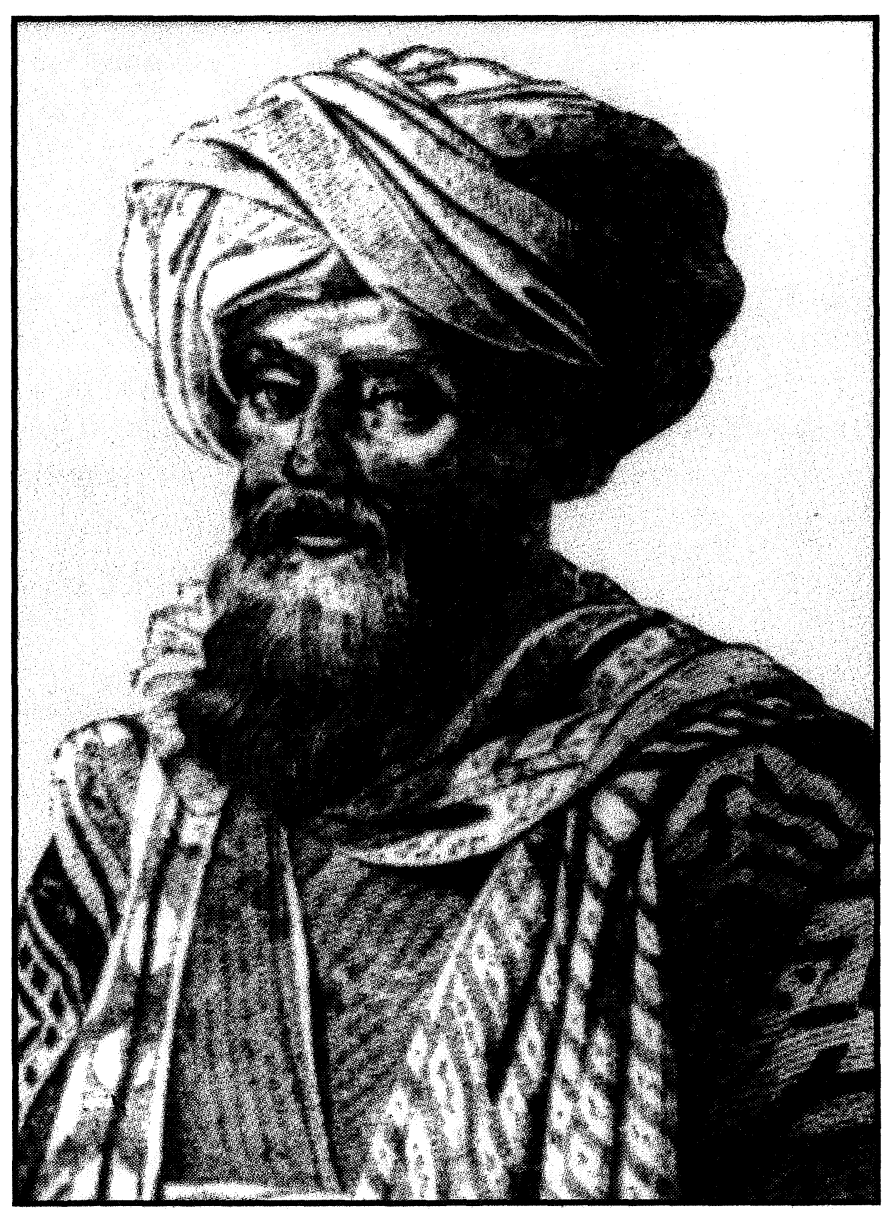

Figura 1. Alí Bey

En los años previos a su viaje a África, desempeñó distintos puestos administrativos. A los catorce años es Administrador de utensilios de la Costa de Granada, y a los diecinueve sucede a su padre en la Contaduría y tenencia de Tesorero del partido de Vera, en Granada. El 26 de septiembre de 1791 se casa con María Luisa Burruezo y Campoy. Con veintiseis años es trasladado a Córdoba como Administrador de la Fábrica de Tabacos.

Desconocemos cómo fue su formación, que tuvo que tener bastante de autodidacta. Pero lo cierto es que conocemos una serie de proyectos y publicaciones que nos hablan del alto nivel intelectual y científico 
que alcanzó. En 1792 presentó un Ensayo sobre el gas y máquinas o globos aerostáticos, y en 1795 el Consejo Supremo de Castilla le concede permiso para construir y hacer volar un globo aerostático, para lo cual crea una especie de Sociedad que lo financia en parte, pero no parece que hiciese volar el aparato. En 1795 dedicó al rey un manuscrito sobre Ensayos sobre la higrometría de Horacio Benedicto de Saussure. En 1799 presentó una Memoria correspondiente al Plan de un Establecimiento que debe titularse Banco de la Real Piedad de Maria Luisa. Una de las carpetas de los papeles de Badía que debe corresponderse con los años 1798 o 1799 lleva el título de Plan de Campaña de Portugal; en su interior un documentalista posterior dice que debió haber papeles que se han traspapelado, pero que una serie de papeles relativos a la marcha de ejércitos forrajes, etc., quizá se refiriesen al mismo plan (la invasión de Portugal, en la "Guerra de las Naranjas» se produjo en 1801).

Llevó a cabo la traducción del Diccionario des merveilles de la Nature del francés Joseph Aignan Sigaud de la Fond (París, 1791) y en abril de 1800, el ministro de Estado autoriza su edición por la Imprenta Real de forma escalonada.

En 1802 presentó el proyecto Diario de los Teatros, que de haberse llevado a cabo hubiese sido la primera publicación española dedicada al arte dramático ${ }^{2}$. Previamente había escrito en 1790 un Discurso sobre la Poesía Épica y excelencia del poema de Telembo, y escribió, posteriormente, la tragedia Alí Bey en Marruecos, en cinco actos.

Con respecto a su estancia en Madrid (aproximadamente desde 1796) donde disponía de pocos recursos, y donde estudiaba y presentaba los proyectos señalados, hay un folio suelto ${ }^{3}$ entre los papeles de Barcelona, que se debió escribir en el proceso de estudio sobre su persona, que señala que durante esta permanencia en Madrid, Badía recorrió todas las bibliotecas. En sus papeles hay numerosos apuntes de títulos de obras, sin duda alguna por él estudiadas. Veía también a los libreros de la calle Carretas, llevando notas de los libros franceses que recibían, y que por su escasez de recursos no podía comprar. Casi todas las obras se refieren a ciencias físicas o matemáticas, y en 1800 comienzan los apuntes de libros de viajes al África. Lo cual nos da una pista de cuándo empezó a interesarse por la que sería su gran aventura.

El 8 de abril de 1801 presentó a Godoy el Plan de Viaje al África con objetivos políticos y científicos, acompañado de un Memorial con carta Geográfica con descubrimientos nuevos, lo cual nos introduce en los vericuetos de su gran viaje, y de todo lo que conllevó. 
La gestación del plan que llevó a Badía a Marruecos, y que después le obligó a abandonar el país (expulsado o huyendo, aunque esto en el texto del libro no queda claro) hacia La Meca, recorriendo Trípoli, Grecia y Egipto; después Palestina, Siria, Turquía para desde Constantinopla regresar a Europa, tal y como narra en su libro, no está muy clara.

Tal y como acabamos de señalar, parece que en 1801 presenta un proyecto para realizar un viaje al África con objetos políticos y científicos. El plan recibió buena acogida por parte de Godoy y se pidió dictamen a la Real Academia de la Historia que lo desestimó. Badía insistió en las posibilidades políticas y de anexiones territoriales, y Godoy aprobó e impulsó el proyecto. De hecho, él, en sus memorias ${ }^{4}$ dice ser el impulsor de un viaje que pasase por científico, al África $y$ al Asia, más cuyo efecto principal sería inquirir los medios de extender nuestro comercio en las Escalas de Levante desde Marruecos al Egipto y hacer los planes e indagaciones para montar nuestro comercio en la región del Asia con entera independencia de los demás potencias europeas ${ }^{5}$... También Badía se dice ser quien concibió la idea, pero tampoco sabemos, de verdad, cuales eran las pretensiones originales.

Tenemos dos versiones, la del libro, donde se narra el viaje de un príncipe musulmán que, criado en Europa, quiere volver con los suyos, y no es sólo bien acogido por el Sultán de Marruecos, sino que éste le trata como a un hermano y es admirado y respetado por el pueblo. Y la que leemos en los documentos del Ministerio de Estado (de Asuntos Exteriores) en la que se está gestando una sublevación contra el Sultán, una vez que éste no es convencido para mejorar su relación con España, y en la que Alí Bey pudo incluso ser alzado al poder. En el momento álgido, cuando incluso armas y soldados estaban ya movilizados, Carlos IV paralizaría la acción. Alí Bey se retiraría de la vida pública y, cuando se le requiere de nuevo para cumplir la misión, su predicamento habría bajado en el país, y lo cierto es que, de modo un tanto oscuro, es embarcado en Larache, sin familia ni séquito, y según el libro de viajes, se dirige a Trípoli.

No tenemos claro ni el cómo ni el porqué, pero lo cierto es que sigue su ruta, no sabemos por ejemplo de donde saca sus fondos o si había sido expulsado. En el libro continúa con sus descripciones de todo tipo y con la narración de un viaje que en principio es la peregrinación que todo musulmán debe cumplir a La Meca. En parte de la documentación se sigue hablando de actividades científicas y actividades políticas en el resto de 
los lugares que recorre, no sólo por Marruecos, pero no puedo especificar en qué consistían.

Lo cierto es que de Trípoli marcha a Alejandría, pero una extraña tormenta le llevará a Chipre, donde permanecerá varios meses, y de donde dejará unas descripciones de sus restos arqueológicos (incluidas láminas) únicas hasta entonces. Llega por fin a Alejandría, la describe de forma admirable, recorre el Nilo, va al Cairo y de allí a Suez, atraviesa el mar Rojo, y continua viaje hasta La Meca.

En La Meca cumple todos los rituales obligatorios y deja una completa descripción (con detalladísimas láminas) de sus templos más importantes, así como de la ciudad. Esto es fundamental, nunca antes un cristiano había descrito de forma tan detallada la ciudad, es la primera vez que se la ubica de forma correcta gracias a sus mediciones astronómicas, y es también la primera vez que se describen y explican todos los rituales que el musulmán debe cumplir en su peregrinación. Este camino, empezando por el disfrazarse de musulmán, es imitado por otros viajeros posteriores, entre ellos Richard Burton.

Es también en este punto del texto donde describe a los wahhabitas de Arabia, que están comenzando su revolución y adquirirán con el tiempo una cuota importante de poder. Después de Arabia marcha a Jerusalén. Aquí hace también una completísima descripción del Haram o templo principal de Jerusalén, construído sobre el antiguo de Salomón, consciente, como dice, de que ningún cristiano puede entrar a visitarlo. Recorre después todos los lugares principales de la cristiandad (curioso, si tenemos en cuenta que se supone que es un musulmán que viene de su peregrinación a La Meca) y marcha después a Damasco y parte de Siria.

De aquí marchó a Constantinopla que también describe profusamente, para terminar su narración con un Estado actual de la Turquía. No es este, sin embargo, el último texto del libro. El viaje de regreso de Alí Bey no es narrado por éste, como hasta ahora, sino por el editor, Domingo Badía, no nombrado directamente, quien narra cómo vuelve el viajero a Europa a través de Bucarest (donde sabemos que Badía estuvo un mes y medio convaleciente) y termina el libro en este punto de forma un tanto abrupta. 


\section{El peregrino Alí Bey, un «príncipe abasí» español del siglo XIX}

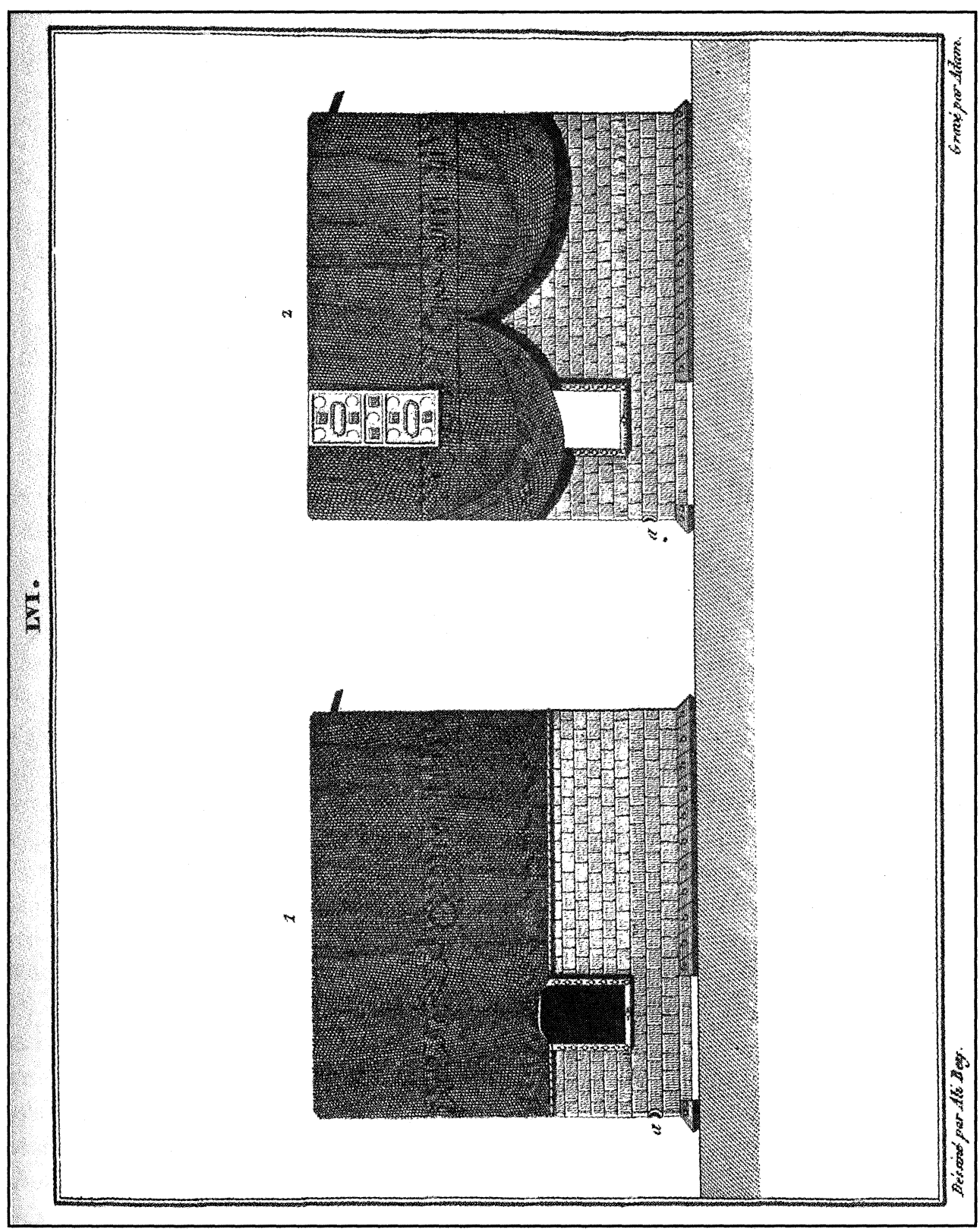

Figura 2. Edificio de la Kaaba. La piedra negra está señalada con la letra «a». El paño que cubre el edificio se llamaba el tob al-Kaaba, y era una especie de cortina que se enviaba cada año desde El Cairo (según Ali Bey) 
Este sería el viaje que cuenta Badía (escrito unos años después), y a partir de aquí cabría recoger los frutos de un viaje para el que había sido comisionado por el Gobierno español, que quizá había fracasado en algunos puntos, pero del que se podrían obtener importantísimos resultados en el futuro. En este sentido, un documento ${ }^{6}$ firmado por el Príncipe de la Paz, dirigido a Pedro Cevallos (Secretario de Estado) para su elevación al Rey, Carlos IV, narra el viaje, dividiéndolo en cinco periodos, para concluir recomendando al viajero, para premiarle adecuadamente, publicar sus viajes, y utilizarle en futuras empresas. El documento está fechado el $1^{\circ}$ de Marzo de 1808 en Aranjuez. El 17 ocurriría el motín que acabó con la figura política de Godoy, y que a la postre desencadenaría todos los sucesos que vendrán en parte luego comentados, y que acabarán con la corona española en manos francesas. El Rey, enterado, según consta en nota, deja en manos de Godoy el premio que él convenga.

En el documento Godoy dice que, según entró el viajero en Europa hace reconocer los papeles que había remitido en diferentes ocasiones y ordenarlos, a partir de lo cual hace subdividir la operación en cinco periodos para su mayor inteligencia. El $1^{\circ}$ comprende todas las diligencias y trabajos preventivos antes de salir de Madrid, varias memorias, los viajes a Paris y Londres, la colección de objetos de historia natural que ofrecí a S.M. y existe en el Real Gabinete ${ }^{7}$ y las travesías de Londres á Cádiz y á Tarifa. El $2^{\circ}$ periodo abraza desde la entrada del Viajero en África hasta su salida de Marruecos... Entre ellos el que mas honra y acredita la sagacidad de nuestro Viagero es el ascendente que llegó a tomar sobre aquellos ánimos, S.M. tiene noticia de ellos, y sabe por que varió el plan y la dirección del viage cuya primera empresa debia ser el reconocimiento de Tomboukt, ... Este $2^{\circ}$ Indice o Periodo pudiera comprender otro genero de noticias y papeles de mucha mayor importancia..., pero la política y los intereses del Estado exigen que se corra un velo sobre varios sucesos, y que queden sigilados y obscurecidos hasta que la voluntad del Rey disponga otra cosa.

El 3er. periodo de esta expedición empieza desde el día en que salió el Viajero de Larache y llega hasta su embarco en el mar Roxo para la Meka. En el nos dá individuales noticias de Trípoli, de la plaza de Modon en la Morea y de la famosa Isla de Chipre. Los trabajos, reconocimientos y que se hizo en esta Isla pueden considerarse como clásicas y originales en todos los sentidos. Tales han parecido también a los sabios del Instituto de Francia (...) A mar de estos trabajos hay otros documentos... el Atlas de su reconocimiento de Chipre con 37 láminas preciosísimas; la descripción de Alexandria de Egipto (...) El $4^{\circ}$ periodo comprende los Viages del Mar Roxo; la Arabia y la Meka, y han producido dos tomos de descripciones; varios cuadernos con notas sueltas, y un Atlas de 36 láminas de objetos no reconocidos hasta ahora, 
ni publicados por Viajero alguno. (...) En poder del Cónsul de Egipto ha dejado depositada una colección de curiosidades recogidas en este periodo de tiempo, que sirven de comprobantes y aumentan el valor de la expedición. El $5^{\circ}$ y último período de esta empresa se compondrá de los trabajos hechos desde su salida del Cayro á Constantinopla, pasando por Jerusalén, Damasco, Alepo, y toda el Asia menor; y de los que ofrece su viage á Viena y producirá su regreso a Madrid. El Indice de este quinto periodo que también acompaña, contiene los documentos que me dice el Viajero conserva en su poder, y cuyos títulos bastan para dar idea de su mérito...

Concluye con una serie de consideraciones sobre el mérito y valor de sus trabajos, más en comparación con el de otros viajeros, para señalar que: Este hombre se halla en el caso de poder hacer grandes servicios al Estado por los conocimientos que ha adquirido; por las relaciones políticas y confidenciales que ha sabido conservar en todas partes y por las importantes miras, $y$ proyectos que ocupan su mente. (...)

Es decir, que a Badía se le abrían grandes posibilidades, pero la caída de su mentor, como hemos señalado, dieron al traste con ellas. Badía llega a París después de su convalecencia y sabe que Carlos IV y Fernando VII se encuentran en Bayona con Napoleón; disputándose y entregando la Corona española al Emperador. En esta situación él menciona que fue el propio Carlos IV, al que vió el 10 de abril, el que le señala que pase a servicio de Napoleón, pues a él pertenece España. Badía se entrevista con él y con su chamberlain, a los que les interesa la aventura ${ }^{8}$ y las posibilidades que abre $\mathrm{y}$, con la promesa de su publicación en francés y español, le ponen al servicio de José I. Fueron tiempos convulsos para recuperar su material y conseguir acreditación ${ }^{9}$ de quien era y que había realizado.

Es significativo, aunque no sé cómo interpretarlo, que durante este tiempo de servicio en la administración de José I siguió vistiendo y comportándose como un musulmán. En una nota al Corregidor de Toledo ${ }^{10}$, la Suprema Junta de Gobierno del Rey reclama su prendimiento, se le describe como «capitán, con largos bigotes, pañuelo abultado y dentro las bambas con sable colgado de un cordón encarnado". Mesonero Romanos señala en su biografía como los habitantes de Córdoba recuerdan su prefecto moro ${ }^{11}$... cumplió distintos cargos y con la caída del «Gobierno Intruso» ${ }^{12}$ hubo de exiliarse en Paris, como tantos otros afrancesados, para nunca volver a España.

Llegó a París a finales de 1812. Los datos sobre su estancia allí no son siempre tan claros, pero sí sabemos que en noviembre de 1813 un resumen de su texto fue examinado por una comisión de la clase de 
ciencias del Instituto de Francia, fue aprobado y se recomendó su publicación, comprometiéndose el Ministro del Interior a comprar 250 ejemplares.

Aquí estamos contando que fué Badía el que publicó, pero lo cierto es que el que firma es Alí Bey, lo escribe en francés, y no se terminó de relacionar ambas figuras de forma clara hasta la edición española de 1836 (veintidós años después). La obra viene dedicada por «el editor B» a Luis XVIII, obviamente el propio Badía, pero no deja de ser curioso, y extraño, no entendemos bien el porqué seguía manteniendo una ficción que ya no le era necesaria.

El libro, en tres volúmenes, viene titulado, como ya hemos señalado, Voyages d'Ali Bey el abbassi en Afrique et en Asie pendant les années $1803,1804,1805,1806$ et 1807, y es publicado en París en 1814. Se completa con un atlas con láminas y explicaciones de las que el autor ha ido realizando a lo largo de todo el viaje. Dos años después, en 1816, aparece la versión inglesa, publicada en Londres, en dos volúmenes que incluyen las láminas con el título de Travels of alí Bey in Morocco, Trípoli, Cyprus, Egypt, Arabia, Syria and Turkey, between the years 1803 and 1807. Se mantiene la ficción de que sea Alí Bey el autor, pero en un Aviso de los Editores ${ }^{13}$, éstos señalan que conocen al autor desde hace años, que viajó como mahometano, y que no se meten en las razones para firmar sus viajes como Alí Bey, es decir, va implícito que es un pseudónimo, como se señala entre paréntesis en la edición de Filadelfia de 1816. También se publicó en alemán: Wiemar 1816; y en italiano: Milán 1816-17. Estas ediciones llevaron el impulso directo del autor (salvo la italiana, que no conoció hasta años después), y debieron suponer algún ingreso, salvo la alemana, que él la consideró ${ }^{14}$ un fracaso por la invasión napoleónica.

La edición española de sus viajes se retrasa hasta 1836. Desde $1833^{15}$, coincidiendo con la muerte de Fernando VII, que nunca lo permitió, se empezó a reivindicar en España la figura de Domingo Badía. Un grupo dirigido y fomentando por Gaspar Remisa, con el nombre de «Junta de Alí Bey" y en la que participan, entre otros, Pascual de Gayangos o Sinibaldo de Mas, investigan su figura, tratan de reunir los documentos que a su respecto estén en el Ministerio de Estado o en otras estancias, y piden información a quien estuvo en contacto con su figura ${ }^{16}$.

Más o menos relacionado con este grupo, lo cierto es que en 1836 se publican en Valencia (el v.1 también se publicará en París y Méjico) en tres volúmenes, pero sin el Atlas, los Viajes de Alí Bey el Abbassi por África y Asia durante los años 1803, 1804, 1805, 1806 y 1807. Traducidos del 
francés por P.P. En la Breve noticia de la vida del autor ${ }^{17}$ que precede el texto se señala, por primera vez de forma explícita, que Domingo Badía y Alí Bey son la misma persona.

Posteriores a estas ediciones, en el siglo XIX, hubo otra en Puerto Rico en 1860, con biografía previa de Mesonero Romanos; y la que, en catalán, el diario La Reinaxensa publicó semanalmente entre el 17 de marzo de 1888 y el 24 de noviembre de 1889. Posteriormente, en 1892, en Barcelona, con notas y apéndice de Jaume Massó i Torrents, se publicó el Atlas dels viatges d'Ali Bey el Abbassi.

Los avatares de las ediciones de su libro, que como se ve, en España dependen de su impulso primero, para luego reeditarse gracias a la reivindicación de su figura como español, y más tarde como catalán dentro del proceso cultural de la Renaixença, nos han apartado de su estancia en París, donde le habíamos dejado.

En octubre de 1815, junto con una memoria con los servicios que había prestado a Francia en Levante, envió al ministro de Asuntos Exteriores, otra sobre "La Colonización de África». Este documento, firmado por Le Général Badía el 21 de octubre, explica su "viaje» por Marruecos, sus pretensiones políticas que albergaban, el contraste con su libro, cómo pasa a gobierno francés, y propone una operación similar a la que hizo, esta vez bajo bandera francesa, continuación, en realidad, de su anterior viaje.

Este texto, publicado en 1930 por P. Roussier, y hasta entonces inédito, permite precisar los últimos proyectos de Badía. Si bien los planes concretos no vienen revelados, se proyecta ocupar asientos en el Magreb, dotar a los naturales de una Constitución ${ }^{18}$ y, si no se encontrase al príncipe adecuado capaz de liderar estas reformas, colocar un europeo disfrazado y con medios. Lo cual es, obviamente, una adecuación versionada de lo que quizá no pudo realizar en su primer viaje. Además, él da como méritos que avalan las pretensiones de este viaje el hijo que allí dejó que cuenta ahora con diez años, que mantiene en Marruecos importantes contactos, e incluso que los beduinos y los habitantes de algunas ciudades, anhelan su regreso.

Roussier además de mostrar su extrañeza porque cien años después no se conoce mucho más el personaje que en su época, ve en Badía un precursor de las constituciones de Marruecos y Túnez, y que prevé cómo se tenían que comportar las potencias europeas en el continente en el siglo XIX para afianzar su papel, como lo están haciendo en el XX (1930).

El proyecto, con variaciones, sale adelante sólo cuando es apoyado por el conde Molé, ministro de Marina, y el conde Decazes, ministro de Po- 
licía. Este proyecto, tal y como es aprobado, propone: $1^{\circ}$. Emprender la travesía entera de África de Oriente a Occidente por su centro y los paralelos diez al quince de latitud norte. $2^{\circ}$. Emplear tres años en el viaje, el primero en la peregrinación a La Meca y los otros dos en la travesía de África, entrando por Abisinia, pasando por Darfur, remontando el curso del Níger y saliendo por Senegal.

Tiene razón S. Barberá ${ }^{19}$ cuando ve tres proyectos para este viaje: el descubrimiento de una vía terrestre hasta la India desde el Mediterráneo oriental, preparar la colonización de África, y el circuito antes mencionado entre Constantinopla - La Meca - San Luis de Senegal.

Lo cierto es que sale de París el 6 de enero de 1818, el 19 de marzo está en Constantinopla y el 23 de mayo en Alepo. Trató de reunirse con lady Lucy Heser Stanhope, que residía en el Líbano, pero sólo se intercambiaron unas cartas. El 4 de julio llegó a Damasco, donde unos días después aparecieron los primeros síntomas de enfermedad. Salió de Damasco con la caravana que le llevaría a La Meca el 17 de agosto, pero empeoró de su enfermedad en el trayecto. Parece que murió en la noche del 31 de agosto al 1 de septiembre, cerca de Zarqa'. Si murió por envenenamiento, con intervención de Inglaterra al respecto, dentro del juego de intrigas y dominio del territorio, como señala la leyenda, o de disentería, consecuencia de un esfuerzo excesivo para la edad que tenia, como señaló por primera vez Torres Amat, no creo que seamos ya capaces de comprobarlo. Cualquier intento por recuperar sus restos, y quizá alguna pista, chocaron con el secreto de la misión, que impedía reclamaciones, y si hubo algo de información en el convento de los franciscanos de Damasco, todo se quemó en 1860.

La leyenda de Alí Bey alcanza también su muerte, fiel reflejo de un personaje único, con una biografía apasionada y apasionante, de cuya aventura conservamos un compendio de sus viajes, que incluye y enlaza estudios científicos (etnográficos, geográficos, de historia de las religiones, del arte, lingüístico...), descripciones valiosísimas e innovadoras, posibilidades colonizadoras que se dieron décadas después; así como un atractivo relato viajero. De los trasfondos políticos e intenciones sabemos menos, o nos quedan puntos no claros, pero conocemos las líneas maestras y, todo junto, hacen del personaje de Domingo Badía, también conocido como el príncipe Alí Bey y como Hayy 'Ali Abu 'Utman (peregrino, padre de 'Utman -su hijo marroquí-), un personaje excepcional en la literatura y en la política españolas, hombre entre varios mundos, el ilustrado y el romántico, el occidental y el oriental, víctima de convulsos tiempos políticos e históricos, protagonista en fin, de una aventura aún no bien conocida ni contada. 
El peregrino Alí Bey, un «príncipe abasí» español del siglo XIX

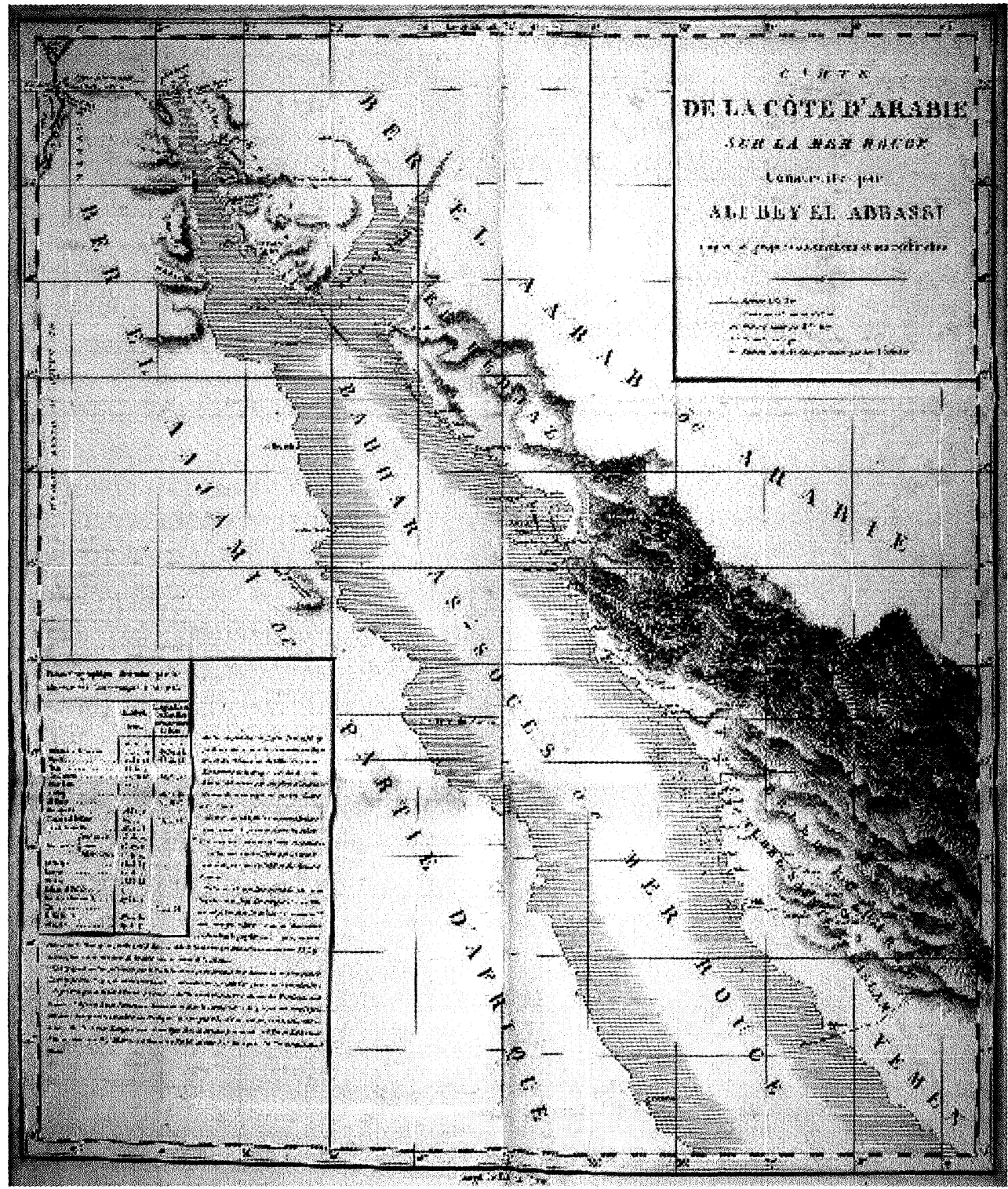

Figura 3. Mapa de Arabia y de Mar Rojo realizado por Alí Bey 


\section{Bibliografía}

A lo largo del texto hemos señalado las primeras ediciones francesa, inglesa y española, además de señalar las realizadas al alemán y al italiano que son traducción del original en francés. Ya en el siglo XIX hubo distintos autores que se ocupan de su persona y de su obra, y aquí vamos a señalar algunos ejemplos. El canónigo Félix Torres Amat (1750 - 1824) en su Memorias para ayudar a formar un Diccionario crítico de los escritores catalanes (Barcelona, 1836, pp. 71-80) elabora un amplio perfil del personaje, y huye de triunfalismos u otros juicios. Mesonero Romanos, más exaltado y patriota, le biografía en Seminario Pintoresco Español, serie II, pp. 65 y ss.; y en la edición de 1860 de Puerto Rico. Victor Balaguer, mucho más prosaico, también le retrata en Jornadas de Gloria. Los españoles en África (Madrid 1860, II, pp. 157-241). Es muy importante lo que cuenta M. Bousset, el Chamberlain de Napoleón, en Memoires anecdotiques sur l'interieur du Palais et sur quelques evenements de L'Empire..., París 1827. Canovas del Castillo también trabaja sobre el personaje, poseyó, como hemos indicado, parte de su documentación y lo trata en Apuntes para la Historia de Marruecos (Madrid 1913). En el siglo XX destacamos la memoria de A. Martín-Gamero: La empresa marroquí de Domingo Badía (Escuela Diplomática, 1946). La introducción a la edición de Compañía Literaria, 1996, por parte de Juan Barceló Luque; y, sobre todo, el trabajo de Salvador Barberá Fraguas, en su edición de los Viajes por Marruecos (Barcelona 1984), sin duda el trabajo mejor documentado y más completo, aunque no comparto la visión negativa que tiene sobre el personaje. A día de hoy se encuentran ediciones del libro sin problemas en el mercado.

\section{Notas}

1 Este es el origen de al menos parte de la documentación que consta en el Arxiu (la noticia del hallazgo de la documentación vino dada en la Revista Catalana, año I, junio de 1889, pp. 300-301), pero en la misma hay también un «Índice de los Papeles de D. Domingo Badía y Leblich, que se encontraba en la Biblioteca del Excmo. Sr. D. Antonio Canovas del Castillo (Manuscrits. Vol. I).

2 S. Barberá, Alí Bey. Viajes por Marruecos. p. 18.

3 Manuscrit I, p. 162.

${ }^{4}$ Príncipe de la Paz. Memorias. Biblioteca de Autores Españoles. Tomo 89, pp. 29 y ss.

${ }_{5}$ Fuese de Godoy, o de Badía, lo cierto es que esta es la idea que a veces trasluce el libro, que después volvería a intentar Badía, que sirvió como referente a otros viajeros y políticos que intentaron lo mismo, y que si parece que recogió y efectuó posteriormente Francia. 


\section{El peregrino Alí Bey, un «príncipe abasí» español del siglo XIX}

6 Archivo Histórico Nacional. Estado, leg. 5803/1.

${ }^{7}$ La documentación que avala esta colección se encuentra hoy en el Museo de Ciencias Naturales de Madrid: «Nota de los objetos de $h^{a}$. natural remitidos al Excmo. Sr. Príncipe de la Paz por los viajeros Dn. Domingo Badía y Leblik y Dn. Simón de Rojas Clemente» Palacio, 24 de julio de 1804.

8 Napoleón envió al capitán Burel a Marruecos en 1808 a, entre otras cosas, comprobar los datos de Alí Bey. Su informe militar corroboraba las informaciones de Alí Bey (J. Caillé, La Misión du Capitaine Burel au Maroc en 1808; Arts en Métiers Graphiques, París, 1953).

9 Entre sus papeles hay una certificación de Amorós de que había sido nombrado Brigadier de los Reales Ejércitos.

10 AHN Estado, L.45 Exp. 188.

11 Sorprende la cantidad de novedades que introdujo en el tiempo que desempeñó el cargo. Introdujo nuevos cultivos, planteó reformas y en el Colegio Real de la Asunción introdujo el Álgebra, la Geometría y la Aritmética en el plan de estudios. Un perfecto ilustrado.

12 Esta es la denominación del período que se utiliza en el Archivo del Palacio Real de Madrid.

13 Printed for Longman, Hurst, Rees, Orme and Brown, Paternoster-row.

14 Tal y como señala a sus hijos en carta.

15 Es también en este año cuando Torres Amat publica sobre el personaje. Ver bibliografía.

16 Un ejemplo claro es la correspondencia entre Pascual de Gayangos y José Camps Soler que se guardan en la Biblioteca del CSIC.

17 Que estaría escrita por Mesonero Romanos.

18 Entre sus papeles del Arxiu de Barcelona hay un proyecto de Constitución.

19 Op.cit. p. 109. 